\title{
4
}

\section{Building capacity: A framework for managing learning and development in the Hong Kong Police Force ${ }^{1}$}

\section{Hon S. Chan and Joseph Wong Wing-ping}

Transforming a government agency into an efficient and effective entity requires a systematic management approach to learning and development as an integral part of workforce planning. The Hong Kong Police Force (HKPF) is regarded as the most efficient and effective civil service unit in the Hong Kong Special Administrative Region Government (HKSARG). This chapter discusses the context and examines the historical evolution of executive development programs in the HKPF. ${ }^{2}$ The prime objective of this chapter is to identify the distinctive training and executive development strategies utilised in the HKPF over the years and to study the way it has transformed itself into a modern and professional police force.

1 The authors are grateful for the generous support from the Hong Kong Police Force in providing all related information and arranging interviews with several senior police officers. Any errors and omissions, however, remain the authors'.

2 While this case study specifically highlights police training in Honk Kong, it is representative of the broader approach to civil service development in the territory. 
While this chapter looks at the training framework of the HKPF, it is appropriate to place this within the context of the overall training policy and strategy of the HKSARG. The objective of the training and development laid down by HKSARG is to enhance individual and organisational performance to maintain and enhance the provision of quality public services. It adopts a two-pronged strategy in the training and development of senior civil servants. At a central level, the Civil Service Bureau, the ministry responsible for the overall management and performance of the civil service, provides high-level and holistic leadership and management training for senior civil servants across bureaus and departments, through the Civil Service Training and Development Institute (CSTDI). For example, the CSTDI organises leadership programs with renowned local and overseas institutions, sponsors high-ranking civil servants to attend courses at reputable universities such as the John F. Kennedy School of Government at Harvard, the London Business School and INSEAD, and also arranges study courses in China. The CSTDI also provides consultancy and advisory services to departments through its team of training officers.

At departmental level, heads of departments are responsible for training and developing their senior civil servants so they have the necessary, and constantly improving, executive capacity for leadership. Given its background and unique position in Hong Kong - as the largest department and one that is always well funded and resourced - the HKPF offers the best example of building executive capacity through a sustainable program of learning and training within a department.

\section{History and development of the Hong Kong Police Force}

Established in 1844, the HKPF has always played an important role in the governance of Hong Kong. Early efforts to build its policing capacities were launched in the 1920s with the creation of the Criminal Investigation Department. In 1930, the HKPF spearheaded the formation of the Emergency Unit, which was designed chiefly to deal with serious crimes and minor disturbances. After World War II, the HKPF reorganised itself by recruiting ex-servicemen from abroad and 
at home. After the 1956 riots, the Police Tactical Unit was formed and given responsibility for maintaining internal security. This enabled the HKPF to develop a permanent reserve for emergencies.

The British Government attached great importance to the development of a quality police force in Hong Kong. In 1893, Francis May, who headed the police force, insisted that every new recruit should go through training in a police college. In 1912, he became governor and ensured that during his term of office, which ended in 1919, the HKPF continued to develop and improve its services.

Half a century later, the paramilitary strength of the HKPF was tested during the riots of 1967, which were a spillover from the Cultural Revolution in Mainland China. For almost a year, handmade bombs were planted throughout the streets of Hong Kong. One day Chinese soldiers opened fire from the border; five Hong Kong policemen were killed in the incident. But the determination of the HKPF and the overwhelming support of the Hong Kong Chinese who chose freedom over nationalism helped put an end to the riots. In 1969, in recognition of the loyalty and outstanding performance of the Hong Kong police, Queen Elizabeth II conferred the title 'Royal' on the force.

The respect the police earned during the riots soon gave way to rampant corruption, which became widespread throughout the HKPF in the late 1960s and early 1970s. This led to the establishment of the Independent Commission Against Corruption (ICAC) in 1974. The government managed to win the war on police corruption not only because of the outstanding and sometimes ruthless job of the ICAC, but also as a result of two significant developments. First, the government raised - substantially - the pay of police officers so they could afford to live comfortably without having to resort to seeking benefits from outside. This policy of paying police officers generously and better than other civil servants has continued to the present day. Second, there was a sense of awakening in the management of the HKPF, which felt the need to inculcate a sense of pride among police officers in their service to the public. Externally, the HKPF has since reached out to various sectors of the community, attended district meetings and set up Junior Police Calls. Internally, the management has been promoting healthy living among its officers and a high standard of honesty and integrity as part of its development programs. 
Within a short span of 20 years, the HKPF became the most respected government department. In July 1997, a month after China's resumption of sovereignty over Hong Kong, according to an opinion poll conducted by the Public Opinion Programme of the University of Hong Kong (HKUPOP), 79.4 per cent of respondents were satisfied with the performance of the police. By comparison, only 44.3 per cent of respondents were satisfied with the overall performance of the HKSARG during the first three months of its establishment.

The new public management trend did not make much of an impact on the civil service sector in Hong Kong. Major management reforms gained momentum mainly with the arrival in 1992 of Christopher Patten, the last Governor of Hong Kong. He brought with him the UK 'citizens' charter' concept of administrative responsiveness and quality service delivery. In response to Patten's initiative, the Service Quality Wing was established within the HKPF in 1994. The Livingthe-Values Workshops, organised mainly for uniformed officers, are the most recent manifestation of the service quality culture. Under this initiative, work improvement teams, station improvement projects and staff suggestion schemes are instituted to drive continuous improvement in service delivery.

Importantly, the handover of Hong Kong to the Mainland did not make much change to the policing system. The Basic Law, which is Hong Kong's constitution, stipulates that the central authorities are responsible for defence and foreign affairs, while the HKSARG is responsible for the maintenance of law and order. Under the principle of 'one country, two systems', the HKPF retains its own policing system, is not connected hierarchically or organisationally with - and, in this sense, is separate from - the Mainland Public Security Ministry or any geographically close divisions (for example, the Guangdong Public Security Bureau). ${ }^{3}$ Since the introduction of this law, HKPF training and development have been set within a professional, organisational and societal context. The force incorporates a number of dynamic driving factors into its training and executive development plan, including

3 This information was provided by a senior police officer in the Hong Kong Police College. We also conducted interviews with several senior police officers in October 2011. Subsequent phone communications were made to either gather additional information or make inquiries about the information provided. To provide an accurate picture of the HKPF's development, this chapter uses the database, documents, reports, statistics and figures given by the HKPF; these sources are quoted directly or paraphrased in some of the discussions in this chapter. 
the volatility of the external environment (the increasing complexity of policing and the policing landscape), HKPF developments (such as the improved calibre of recruits in recent years and, as a result, the increased expectations on training and development) and customer and government expectations (rising demands for a responsive and responsible police service) (see Hong Kong Police College 2008b).

\section{Force management structure}

The HKPF is a large organisation with more than 27,700 uniformed staff in 12 different ranks. ${ }^{4}$ Because of Hong Kong's history-as a colony of the United Kingdom and, since 1997, a Special Administrative Region of the People's Republic of China - the HKPF is the principal law enforcement agency as well as the agency of first response and last resort. Its portfolio of duties covers a wide spectrum including crimefighting, public order maintenance and internal security.

There are two entry-level ranks in the force: constable and inspector. New recruits normally join the force between the ages of 18 and 23 . The normal retirement age is 55 , or 57 for those in the senior directorate. As is the case in other metropolitan police forces, here there are different career streams such as frontline policing, special operations, criminal investigation and administrative and management-related duties.

The Commissioner of Police is charged with the supreme direction and administration of the police force under Section 4 of the Police Force Ordinance, Chapter 232. The commissioner is subject to the orders and control of the Chief Executive of the HKSARG. Under his administration, there were 433 gazetted officers, 2,159 inspectorate officers and 25,323 junior police officers, with 3,858 civilian staff in 2010 (see Table 4.1, the headline figures represent total staff including officers on pre-retirement leave, while figures in brackets indicate actual staff numbers of police at each level).

4 The most up-to-date figure is 27,700 , provided by another senior police officer in our interview conducted on 4 October 2011. The figures in the following discussion were drawn from the Hong Kong Police Review 2010 (HKPF 2010); they are therefore 2010 figures. 
The Senior Directorate Group (SDG) is the executive body of the HKPF. It comprises two deputy commissioners of police (operations and management), four senior assistant commissioners of police and one civilian officer of equivalent rank. The last five SDG members mentioned are program directors of operations, crime and security, personnel and training, management services, and the civilian director of finance, administration and planning. Fourteen assistant commissioners, one police civil secretary (a general civil service grade with the rank of senior principal executive officer) and one financial controller (a departmental civil service grade with the rank of assistant director of the treasury department) assist the commissioner and his SDG members. Another 401 gazetted officers variously hold the ranks of chief, senior superintendent and superintendent. This group of gazetted officers is the core executive group of the HKPF.

In brief, the governance of the force starts with the commissioner and the SDG. Policy direction cascades down to frontline commanders and officers through various schemes including the Hong Kong Police Force Vision and Statement of Common Purpose and Values, the Controlling Officer's Report, the Strategic Action Plan and the Commissioner's Operational Priorities. Daily policing activities follow the HKPF's policy direction in the form of regional, district and divisional plans.

Table 4.1: Establishment and actual strength of the Hong Kong Police Force, 2005-10

\begin{tabular}{|l|c|c|c|c|c|c|}
\hline & 2010 & 2009 & 2008 & 2007 & 2006 & 2005 \\
\hline $\begin{array}{l}\text { Gazetted } \\
\text { officer }\end{array}$ & $\begin{array}{c}433 \\
(422)\end{array}$ & $\begin{array}{c}430 \\
(426)\end{array}$ & $\begin{array}{c}423 \\
(418)\end{array}$ & $\begin{array}{c}422 \\
(411)\end{array}$ & $\begin{array}{c}401 \\
(419)\end{array}$ & $\begin{array}{c}411 \\
(412)\end{array}$ \\
\hline Inspectorate & 2,159 & 2,162 & 2,145 & 2,138 & 2,101 & 2,132 \\
& $(2,230)$ & $(2,218)$ & $(2,176)$ & $(2,139)$ & $\begin{array}{c}2,142) \\
(2,161)\end{array}$ \\
\hline $\begin{array}{l}\text { Junior police } \\
\text { officer }\end{array}$ & 25,323 & $\begin{array}{c}25,142 \\
(25,334)\end{array}$ & $\begin{array}{c}24,770 \\
(25,216)\end{array}$ & $\begin{array}{c}24,779 \\
(25,001)\end{array}$ & $\begin{array}{c}24,419 \\
(24,813)\end{array}$ & $\begin{array}{c}23,969 \\
(24,831)\end{array}$ \\
\hline Total (strength) & 27,915 & $\begin{array}{c}27,734 \\
(27,978)\end{array}$ & $\begin{array}{c}27,338 \\
(27,810)\end{array}$ & $\begin{array}{c}27,339 \\
(27,551)\end{array}$ & $\begin{array}{c}26,921 \\
(27,374)\end{array}$ & $\begin{array}{c}26,512 \\
(27,404)\end{array}$ \\
\hline
\end{tabular}

Source: HKPF (2010). 


\section{HKPF Steering Committee on Human Resource Management}

The HKPF Steering Committee on Human Resource Management (and its predecessor, the Policy and Coordinating Committee on Force Training and Development) is the main human resource management (HRM) body in the HKPF. The terms of reference for the steering committee outline its main tasks:

- To steer and monitor the implementation of established HRM policies in support of the Force Vision, Common Purpose and Values.

- To consider proposed policies on HRM to ensure alignment with HKPF objectives and strategic directions.

- To review and update HRM policies to ensure they meet the changing needs of the HKPF and the community it serves.

- To oversee new HRM-related initiatives to ensure alignment with the HKPF's strategic framework.

- To oversee new course/development initiatives and, where appropriate, make recommendations to ensure alignment with HKPF objectives and strategic directions.

- To recommend, where appropriate, the allocation of resources for local/overseas training courses for vocational/development purposes and to ensure the principle of value for money is applied. ${ }^{5}$

The steering committee has 12 members and is chaired by the Director of Personnel and Training - a senior assistant commissioner position. The personnel wing of the HKPF and the police college are the executive arms of the steering committee. With a uniformed staff of 27,770, the HKPF has 729 training staff. There are 509 officers working in the Hong Kong Police College, 135 in the Police Tactical Unit Headquarters, 57 in the Training and Staff Relations Office and 27 in the Marine Police Training School. Together they provide expert assistance in training and development policies to major formation commanders as required, coordinate the Force Training and Development Plan and report on and maintain the Force Training

5 Information provided by the HKPF on 11 October 2011. 
Directory, evaluate feedback from major formation commanders on training and development needs and perform environmental scans to select topical training subjects (see Hong Kong Police College 2009).

\section{Methodology of training and development}

\section{The 'learning trio'}

As shown in the Training and Development Plan 2006-08 formulated by the then Policy and Coordinating Committee on Force Training and Development, the prevailing training philosophy of the HKPF is that 'effective training and development can foster a continuous learning culture and realise the potential of its officers to meet the needs of the Force and the community it serves' (Hong Kong Police College 2006: 8). Promoting the 'learning trio' within the HKPF reinforces this continuous - that is, lifelong - learning culture (see Figure 4.1). Three key components underline this training trio. Induction training, which, together with other mid-career programs, is perceived as formal training, is the first component. About 25 per cent of all police officers' learning is acquired through formal training.

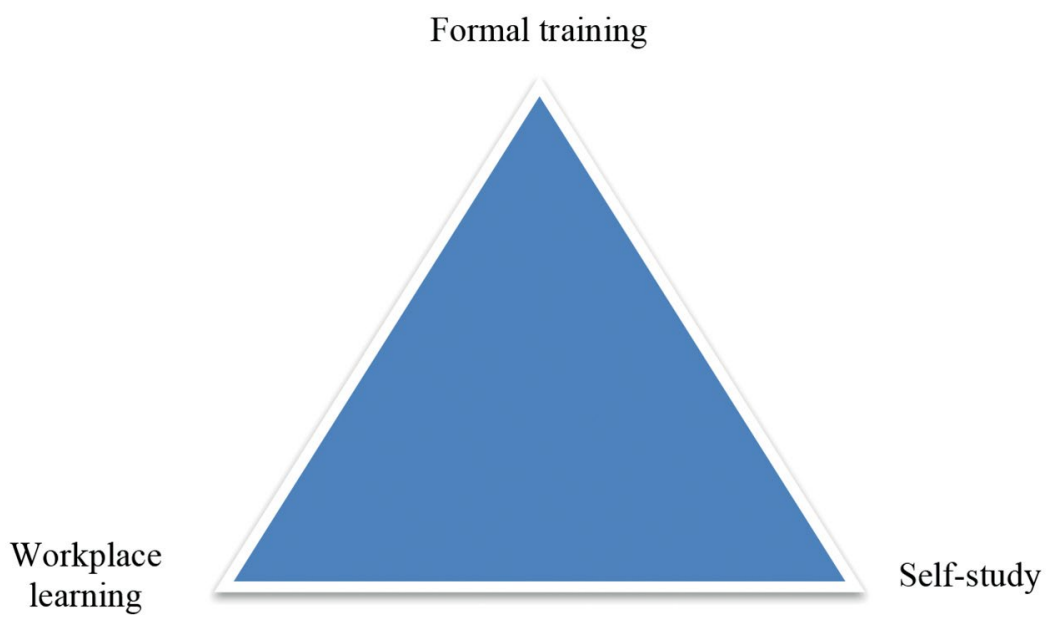

Figure 4.1: The 'learning trio'

Source: Created by the authors. 
Apart from organising formal structural programs, the police college helps to support workplace learning and self-study. Learning takes place not only within the formal classroom setting; police officers gain workplace learning from work experience, interaction with peers and job assignments.

In relation to job assignments, the HKPF has stepped up measures to carry out a comprehensive program of training and executive development for all police officers. Police officers will take up mandatory or structured postings as assigned to ensure full exposure to the various aspects of workplace experience in the force. Police officers are encouraged to indicate their preferences for postings at a certain point in their career. The HKPF has also identified police officers with potential - that is, those who demonstrate excellent performance in formal training and receive an outstanding performance rating - for various ranks and has tailored their career advancement accordingly. On the job, officers receive ample coaching and mentoring from their supervisors. To facilitate quality peer coaching, the police college implements training of junior police officers for supervisory roles. Other HKPF initiatives include schemes for mentoring potential officers and tutoring police constables.

Self-study is regarded as being as important as following a structured curriculum. Learning is both an organisational and a personal responsibility. Given this understanding, the police college works on the principle that police officers must function as active knowledge promoters and learning facilitators. All police officers are required to share their experiences with other members and coach subordinates and peers within their areas of expertise. In short, they must not only learn, but also help other police officers learn. Apart from adopting a self-study approach for individual development in the HKPF, the police college supports continuous learning through organising formal seminars and providing financial subsidies. Many such ad hoc learning programs are scheduled outside office hours so that interested officers attend these programs in their own time. Reimbursement of course fees for short local courses helps police officers, particularly junior officers and junior inspectors, to engage in learning mostly by way of completing a bachelor or master's degree in their own time. Academic accreditation of training from local as well as overseas 
tertiary institutions is a further step to encourage officers to pursue higher university qualifications in policing and other related disciplines. ${ }^{6}$

\section{Training hierarchy}

A senior police officer explained, in an interview with the authors conducted on 4 October 2011, a strategy to groom future leaders within the force by developing the skills and competencies of staff through a tiered hierarchical approach to training and development, which is another important methodology in training and executive development of the HKPF (see Figure 4.2).

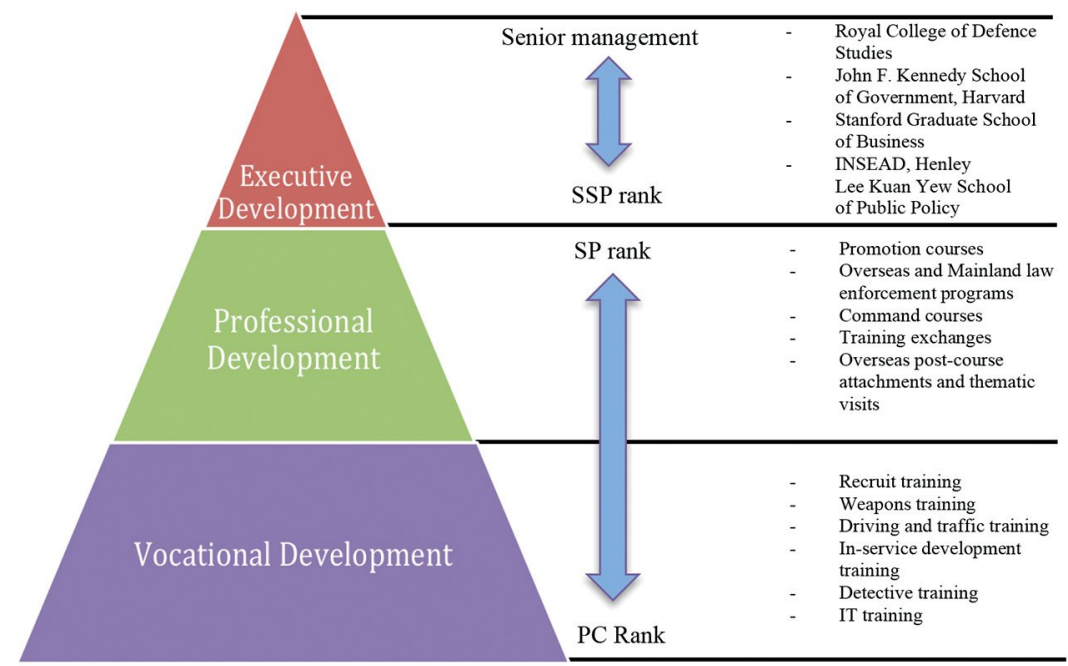

Figure 4.2: The police training hierarchy

Source: Created by the authors. $\mathrm{PC}=$ police constables; $\mathrm{SP}=$ senior police officers; and $\mathrm{SSP}=$ senior superintendent police officers .

The first tier emphasises vocational training, which begins with induction or foundation courses on appointment to the HKPF. These courses provide officers with the practical job-based skills to prepare their career. The force also arranges specialist and mid-career training programs that are open to all ranks of police officers throughout their service. In alignment with the 'learning trio' concept (illustrated in

6 Information gathered from interviews with senior police officers on 3 October 2011. 
Figure 4.1), the HKPF has developed a workplace learning strategy to encourage personal development through job rotations, mandatory or structured career paths, mentoring and coaching. The HKPF rotates officers on a regular basis - normally every two to three yearsto enable them to experience a broad range of police duties in regional units as well as at police headquarters. To supplement this policy, the force has introduced career paths for junior inspectors so they can indicate their preferred posting and gain exposure to the full range of core police functions at an early stage. Mentoring and coaching both on a formal and an informal basis are crucial for passing on institutional culture and learning experience. On a day-to-day basis, this primarily involves line supervisors and colleagues at two levels in the hierarchy. On a more formal basis, the HKPF has created a peer advisory scheme accessible via the police intranet, whereby staff can consult a group of experts in areas such as public order policing and crime investigation.

The second tier of professional development refers to training and development in generic competencies such as police management and leadership skills. This is pursued both internally through promotion and command courses and externally by sending officers on overseas training attachments, to international conferences or accompanying senior directorate officers to international conferences. All newly promoted officers will be required to attend command courses at their respective levels, to equip them with updated professional knowledge, leadership and management skills, as well as knowledge of the political, economic and social matters important to the service delivery of the HKPF. Supplementing the learning experience from vocational and professional development, the HKPF arranges for officers to attach themselves to overseas and Chinese provincial police forces for experience sharing, updating professional knowledge, developing an international perspective and networking. The force also regularly dispatches teams of officers of different ranks to visit overseas police forces to broaden their vision and engage in international dialogue. Locally, the HKPF has seconded officers to government departments and related educational establishments. For example, in recent times the HKPF has seconded officers ranging from the rank of constable to senior superintendent to the Security Bureau, Department of Health and Hong Kong International Airport Authority. International secondments have included postings to the 
Interpol General Secretariat in Lyon, France, the Interpol Liaison Office in Bangkok, the UK National Policing Improvement Agency and the Chinese People's Public Security University in Beijing.

The third tier of executive development gives emphasis to areas such as strategic planning, policy analysis and development of strategic vision. Newly promoted senior superintendents and above are required to attend the Management Development Program, which is designed internally and comprises regular seminars and modular training workshops for the sharing of strategies to meet challenges in the HKPF and the civil service, the development of more advanced management skills and broadening horizons on contemporary issues. Externally, the HKPF tailors the executive development programs and sends senior police officers to courses through its Overseas Development Training (ODT) and Mainland Development Training (MDT) programs organised by institutions in the United Kingdom, the United States, Australia, Austria, Canada, Germany, Indonesia, Malaysia, the Netherlands, Singapore, Sweden, Switzerland, Thailand and Mainland China. These programs help to develop the critical thinking skills and global perspectives required of a future leader of the HKPF. ${ }^{7}$ The HKPF planned to expand ODT places from 121 in 2010-11 to 142 in 2011-12, and MDT places from 252 in 2010-11 to 366 in 2011-12, representing an increase from 373 places to 508 (a 27 per cent increase) across the two programs. ${ }^{8}$

\section{Key components of training and development in the HKPF: Command courses}

Three types of command courses make up the three key components of training and executive development of the HKPF. These courses are run by the Hong Kong Police College. The paper A Conceptual Framework for Command Courses, developed by the police college in 2011, clearly spells out the pedagogy, the conceptual framework, the course design and other related aspects of the three command courses (Hong Kong Police College 2011a). In the interests of space, this chapter addresses the conceptual framework, course design and the tentative schedule of the three command courses to be offered in

7 Information from an interview with a senior police officer on 4 October 2011.

8 Information given by the HKPF on 12 October 2011. Figures in 2010-11 are current, while those for 2011-12 are estimates. 
2011-12, to put the discussion in perspective. Before going further, it is important to note that the three command courses are designed to cater for the training and development needs of police officers in their respective ranks. The Junior Command Course (JCC) is designed mainly for junior police officers. The Intermediate Command Course (ICC) is for police officers holding a rank of chief inspector or above. The Senior Command Course (SCC) is for police officers of a rank of superintendent or above.

\section{Conceptual framework}

For many years, the HKPF has been moving away from a curriculumcentred approach towards a more problem-based approach (see Figure 4.3). In shifting the emphasis, there is a need to balance actual workplace experience with theoretical knowledge. Traditional classroom face-to-face learning, while remaining useful for experience sharing and learning theoretical knowledge, tends to give a rather restricted perspective on work in a police setting. Hence classroom learning has to be supplemented with hands-on, job-based practice and problem-motivated learning in policing. It is believed this helps build confidence and competence in problem-solving among police officers.

\section{Curriculum-centred approach}

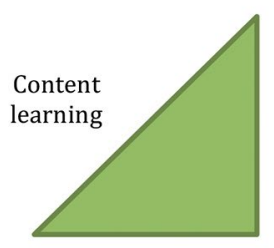

Trainee as apprentice

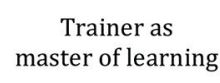

\section{Problem-based approach}
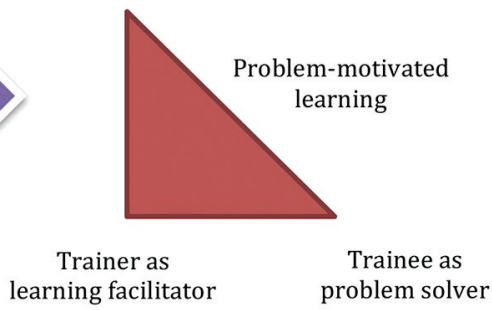

Figure 4.3: From a curriculum-centred approach to a problem-based approach

Source: Created by the authors.

Problem-based learning seeks to develop officers' analytical powers, critical thinking and decision-making skills while simultaneously giving them real-life situations and a safe environment in which to learn by trial and error. Learners are required to apply problemsolving skills to identify the problem and assess the time, information and resources needed for its solution. 
There are many adult-learning theories that have been incorporated by the HKPF in the development of these three command courses. Some learning theories are presented in the conceptual paper. The first example is the transformative learning theory. Research has shown that transformative learning produces different individual, interpersonal and organisational outcomes. Transformative learning involves questioning assumptions as well as unlearning habits, behaviours and beliefs that are either outdated or no longer useful. Hence, the command courses must provide participants with the ability to question existing beliefs and the skills necessary to assess the validity of these assumptions.

The other examples of learning theories are action learning and action research. Action learning requires the learners to discuss real-world problems. They are then asked to apply both critical thinking and communication skills that assist in the transfer of learning into the workplace beyond the confines of the teaching environment. Action research as a requisite tool for action learning has gained increasing popularity in the HKPF as a way of contributing to ongoing professional development. This theory emphasises self-reflection and self-evaluation during and after problem-solving episodes. This learning style maintains that the individual is fully aware of their responsibility for their own actions. With this awareness, individuals will presumably improve their self-management as well as professional skills (see Hong Kong Police College 2011 a: 2-3).

\section{Design of command courses}

The focus of each level of command course will differ substantially. The HKPF has sought to provide a continuum as officers advance through each command course with promotion. There are two ways to explain the differences. Since different stakeholders naturally hold different views about what is worthy of inclusion in the curriculum, the HKPF proposes a broad focus for each level of command course, as follows:

- JCC: Broad introduction to all three modules (leadership and self, context of policing and organisational effectiveness) with an emphasis on operational issues.

- ICC: Refresher on three modules with focus on staff issues including motivation, team building and translating organisational strategies into practical and effective activities. 
- SCC: Refresher on three modules with a focus on creating public value through strategic planning and the implementation process (see Hong Kong Police College 2011a: 4).

A different way to illustrate the difference is by comparing the degrees of emphasis each command course puts on personal development, professional development and vocational development (see Figure 4.4).

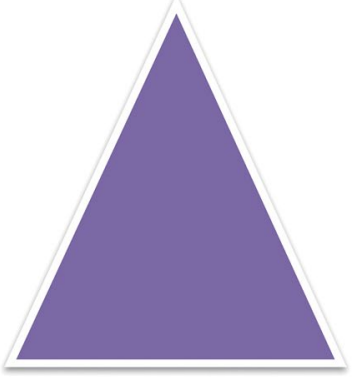

JCC

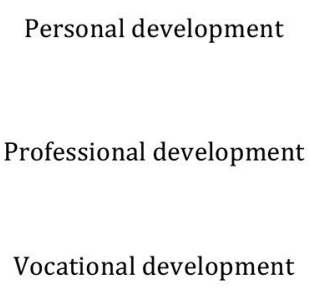

ICC

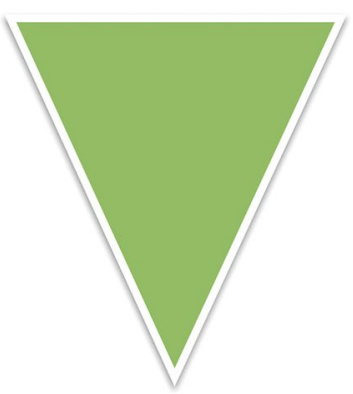

SCC

Figure 4.4: The degree of emphasis between personal, professional and vocational development in each command course

Source: Created by the authors.

Personal development refers to the extent of a person's self-awareness. Learners (or participants) are made aware of the fact that command courses are developmental in nature, with the objective of enhancing the leadership performance of junior and middle managers in the HKPF. In alignment with the theories of action learning and action research, self-awareness requires learners to be aware of their own behaviour and style so they know whether they are following best practice in modern management. They are assisted in this selfdiscovery process by psychometric testing. Two of these instruments are used in the SCC and ICC: the Myers-Briggs Type Indicator (MBTI) and the Harrison Assessment. Only the MBTI is used in the JCC. Psychometric profiling aside, learners are exposed to self-analysis through on-camera experiences including media training, knowledge sharing, presentations and classroom-based exercises. Arrangements are made for learners to meet with outsiders to enhance their social sensitivity and awareness of the outside world. Courses selected for this developmental area also cover the core competency requirements for 'personal effectiveness' and 'communication'. At the SCC and ICC 
levels, the theory and craft of leadership are included and delivered mainly through a project and an experiential learning-based approach. Small project teams work on topics covering areas such as leadership theory, motivation, policing models, a change environment and different methods of strategic policy formulation. At the SCC level, emphasis is given to 'strategic leadership'.

Professional development refers to those modules designed to enhance learners' understanding of their relationship with the organisation and the various principles under which the organisation operates. It includes field trips to both internal police formations and other police forces in greater China. Modules selected for this developmental area cover the core competency requirements for professionalism.

Vocational development covers policies, practices and procedures affecting everyday life. In general, the SCC does not focus on this area, while the JCC puts the greatest emphasis on vocational development. Figure 4.4 shows that the amount of time spent on vocational learning in the SCC is inversely proportional to that spent in the JCC. The objectives of all courses are aligned with the above schema (Hong Kong Police College 2008a).

\section{Frequency of command courses, 2011-12}

All command courses ran for three weeks with a one-day visit to the Mainland, except for the SCC, for which a two-day visit was scheduled. The HKPF organised six JCCs between April 2011 and March 2012, five ICCs between May 2011 and June 2012 and three SCCs between May 2011 and March 2012. Between 15 and 18 participants took part in each command course. The JCC included participants from the Guangdong Public Security Bureau. Both the JCC and the ICC included participants from other Hong Kong Government Disciplined Services. External participants from other jurisdictions have been availing themselves of reciprocal opportunities in the SCC. For example, in SSCs held in November 2007, there were five such officers, one each from China, the United Kingdom, Australia, the Netherlands and Singapore. ${ }^{9}$

9 Information gathered from interviews on 3 October 2011. 
The HKPF does not have any plans to align command courses with one another or with any other course provided in-house-for example, the Course on Basic Training or the Inspectors' Continuation Course. The chief reason is the long time lapse between an officer's participation in each of these courses, which means any alignment would not necessarily lead to consistency in the learning experiences of participants. For example, by the time a JCC participant attends the ICC, an average of eight years has passed, by which time the original JCC will have changed in content and emphasis; the ICC cannot be aligned with both the original course and the new course. The second aspect of alignment is to decide whether officers at all levels should be taught using the same principle. Given the nature of work, scope of responsibility and degree of authority and discretion given to police officers of different levels, variations within the three command courses are expected.

\section{Training loading and resources support in training and development}

How does the HKPF invest in training and executive development, particularly the three command courses identified as the key elements? Where are the funding streams? How does the level of funding affect the staff and faculty conducting training and the quality of training delivered? What are the training costs? The following discussion uses the database and report provided by the HKPF and the authors' interview findings to address some of these questions.

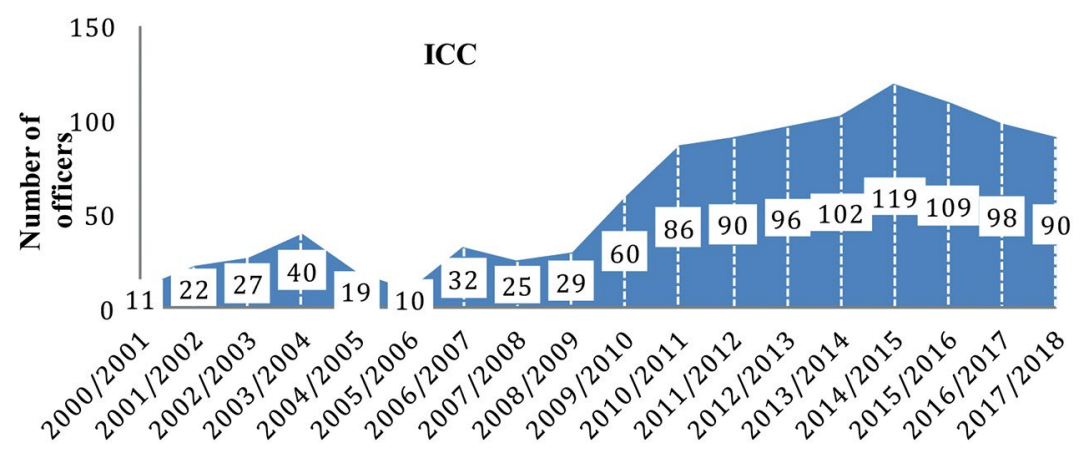

Figure 4.5: Number of officers to be trained in the Intermediate Command Course (ICC), 2000-01 to 2017-18

Source: Created by the authors (see footnote 3 above and the list of reports provided indicated in the reference list). 
Figure 4.5 shows the number of officers and the percentage of each rank to be trained in the next four years of the ICC. Table 4.2 summarises the training targets of the three command courses for the years 2011-12 to 2013-14.

Table 4.2: Training targets of the three command courses, 2011-12 to $2013-14$

\begin{tabular}{|l|c|c|c|}
\hline & $2011-12$ & $2012-13$ & $2013-14$ \\
\hline JCC & 108 & 186 & 212 \\
\hline ICC & 90 & 96 & 119 \\
\hline SCC & 54 & 56 & 66 \\
\hline
\end{tabular}

Source: Hong Kong Police College (2011b).

Figure 4.6 indicates the budget (the money available to cover training contractors, presenters, training materials and the like) for the three command courses between 2006-07 and 2011-12. Figure 4.7 presents the average budget per officer trained for the three command courses over the same period, calculated by dividing the total budget by the number of participants. Note that the budget does not increase in line with the growing number of officers trained.

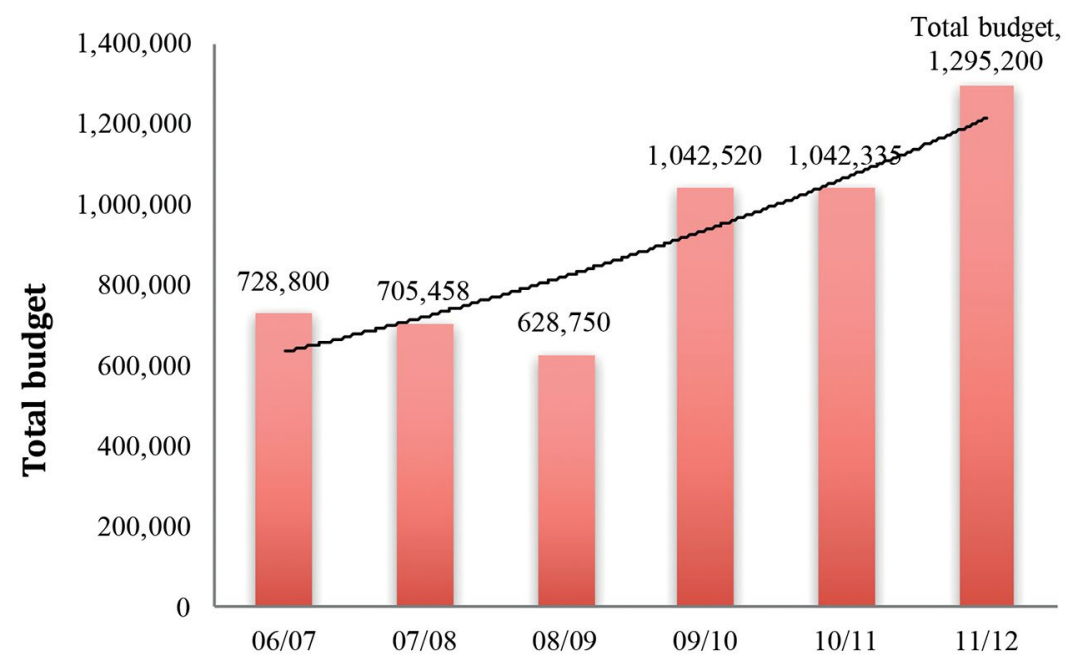

Figure 4.6: Total budget for running the three command courses, 2006-07 to 2011-12

Source: Created by the authors. 


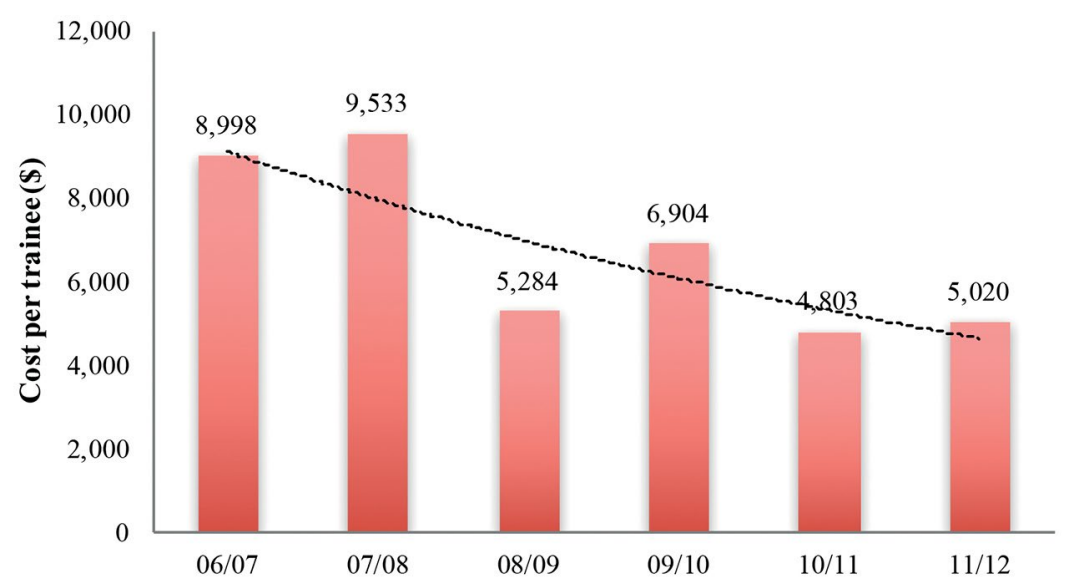

Figure 4.7: Budget for running the three command courses per officer trained, 2006-07 to 2011-12

Source: Created by the authors.

The investment in each command course cannot be measured simply by looking at the budget. Instead, the time-cost for participants should also be incorporated. The time-cost (as of October 2011, based on 18 officers per three-week command course) is as follows:

- SCC: HK\$1,037,796 (A $\$ 173,544)$

- ICC: HK\$864,145 (A $\$ 144,505)$

- JCC: HK\$625,911 (A\$104,667).

Based on a two-week course, the time-cost is as follows:

- SCC: HK\$691,864 (A $\$ 115,696)$

- ICC: HK\$576,094 (A\$96,336)

- JCC HK\$417,274 (A\$69,778). ${ }^{10}$

The HKPF has also organised the Overseas and Mainland Development Training (OMDT) and Overseas Vocational Training (OVT) programs. Before the start of each financial year, the HKPF sources appropriate courses for officers. The Financial Comptroller will allocate a lump sum to cover OMDT expenses. The OMDT is open to all ranks while the OVT is designed for specific purposes, usually to meet the formation

10 Information provided by the HKPF on 3 October 2011. 
commanders' needs. The personnel wing of the HKPF is given responsibility for nominating suitable officers to attend the OMDT. The Deputy Commissioner (Management) endorses the proposed nomination and the allocation of OMDT. The Director of the HKPF endorses the proposed nomination and the allocation of OVT.

Included in the list of institutions for the overseas development programs are seven from the United Kingdom, six each from the United States and Australia, four from Canada and one each from Austria, Germany, Indonesia, Malaysia and the Netherlands. Examples of courses offered by these institutions are the Executive Leadership Program, Police Officers' Command Course, Law and Enforcement Management Program and International Fellow Exchange Program. Seventeen institutions in China are listed in the Mainland Development Training, including the National School of Administration of China, Chinese People's Public Security University and local police colleges and universities such as Sun Yat-sen University, China Foreign Affairs University, Peking University and Tsinghua University. These institutions offer courses in their (Advanced) National Studies Program, National Strategies Program, Police College Study Program, and so on. ${ }^{11}$

For the year 2011-12, 77 police officers were to be nominated to take part in the OVT program. At the time of writing, eight officers at or above the rank of superintendent, 50 inspectorate officers, 15 junior police officers and two technical staff had been nominated, with two further nominations pending. ${ }^{12}$ Officers will be sent to Thailand (21 places), Singapore (20 places), the United States (12 places), the United Kingdom (11 places), Canada (four places), Mainland China (three places), Australia (two places) and Germany, Switzerland, New Zealand and Indonesia (one place each).

The HKPF has sent police officers to attend courses organised by the CSTDI. In 2010-11, 24 seminars (10 of which focus mainly on current issues in Hong Kong and China and 14 on vocational topics) and 49 job-related (to civil service) programs were organised. The CSTDI does not charge the HKPF for running all these courses because they are not police-specific. ${ }^{13}$

11 Information provided by the HKPF on 11 October 2011.

12 Information provided by the HKPF on 3 October 2011.

13 Information provided by the Hong Kong Police College on 12 October 2011. 


\section{Funding streams for training and development programs}

The key service provider in the HKPF is the Hong Kong Police College. The Superintendent Management Learning Division (SMLD) is responsible for organising and running the ICC and SCC. A chief inspector and a non-civil service contract officer (with a grade of senior training manager, STM) assist the SMLD. The chief inspector and STM are responsible for organising and running the JCC. The HKPF uses external facilitators to help meet the heavy demand for the three command courses. In general, there are five types of facilitators:

1. internal (HKPF) facilitators

2. government speakers (mainly policy-level administrative officer grade)

3. guest speakers (prominent personalities in society)

4. consultants (paid on a commercial rate)

5. academics (paid an honorarium).

Table 4.3 presents the Hong Kong Police College's 2010-11 expenditure and projected expenditure for 2011-12.

Table 4.3: Expenditure of Hong Kong Police College (HK\$)

\begin{tabular}{|l|c|c|}
\hline & \multicolumn{2}{|c|}{ Year } \\
\hline Items & $2010-11$ & $2011-12$ (projection) \\
\hline Salary & $297,913,000$ & $249,372,930(-16 \%)$ \\
\hline Local training & $16,204,000$ & $15,215,400(-6 \%)$ \\
\hline Overseas training & $8,426,060$ & $6,766,000(-20 \%)$ \\
\hline Mainland Exchange Program & 976,000 & $700,000(-28 \%)$ \\
\hline Administration and other & $41,453,669$ & $38,488,849(-7 \%))$ \\
\hline Total & $364,972,729$ & $310,543,179(-15 \%)$ \\
\hline
\end{tabular}

Source: Created by the authors.

The HKPF has a special account to meet the costs of OMDT and OVT. Tables 4.4 and 4.5 present training statistics and expenditure for both programs. ${ }^{14}$

14 Information provided by the HKPF on 3 October 2011. 
Table 4.4: Overseas and Mainland Development Training (OMDT) program

\begin{tabular}{|l|c|c|c|c|c|}
\hline & $2006-07$ & $2007-08$ & $2008-09$ & $2009-10$ & $2010-11$ \\
\hline Number of courses & 61 & 68 & 69 & 62 & 75 \\
\hline Number of participants & 256 & 289 & 327 & 306 & 339 \\
\hline $\begin{array}{l}\text { Actual expenditure } \\
\text { (HK\$) }\end{array}$ & $5,615,662$ & $5,370,101$ & $6,048,505$ & $5,110,746$ & $7,319,577$ \\
\hline
\end{tabular}

Source: Created by the authors.

Table 4.5: Overseas Vocational Training (OVT) program

\begin{tabular}{|l|c|c|c|c|c|}
\hline & $2006-07$ & $2007-08$ & $2008-09$ & $2009-10$ & $2010-11$ \\
\hline Number of courses & 42 & 52 & 43 & 63 & 75 \\
\hline Number of participants & 50 & 74 & 57 & 87 & 135 \\
\hline $\begin{array}{l}\text { Actual expenditure } \\
\text { (HK\$) }\end{array}$ & 983,780 & $1,606,906$ & $1,333,088$ & $1,962,665$ & $3,328,739$ \\
\hline
\end{tabular}

Source: Created by the authors.

It is clear that the HKPF has allocated funding based on organisational priorities. All strategies are fully costed, including taking into account the indirect time cost to participants. Key training responsibilities are clearly articulated. Nonetheless, if the current training format for the three command courses remains unchanged, the HKPF will need to create 11 courses for the JCC, seven for the ICC and four for the SCC to meet its 2012 training targets. This would require a JCC almost every month of the year and either an ICC or an SCC every month. This kind of overlap raises the management issue of who will act in a rank if two ranks are attending courses at the same time. ${ }^{15}$ Moreover, the data show that if the HKPF wants to maintain its momentum in training more middle-ranking and junior police officers, resources will be a problem. A 15 per cent cut to the budget was expected for the financial year 2012-13, and the HKPF will need to find a way to deal with reduced funding.

15 Interviews conducted on 3 October 2011. 


\section{Training content}

The training curriculum of the HKPF covers all aspects of modern training and executive development theories and strategies. A very clear methodology underlines the three command courses, covering three modules: leadership and self, context of policing and organisational effectiveness. Varying degrees of emphasis on personal, professional and vocational development are built into the course design.

The seminars and programs organised by the CSTDI are designed to brush up officers' language, communication, management and other job-based skills. Additional topics offered by the CSTDI include:

- understanding China and Hong Kong

- civil service reform in China

- performance measurement and management in China

- socialist, command and basic law

- administrative law and judicial review

- enhancing gender awareness

- understanding of the Equal Opportunities Ordinance

- alternative dispute resolution (mediation and arbitration) and its application

- emotional intelligence in action

- executive health and stress management

- managing conflict

- capital work expenditure

- HRM

- supervisor management skills

- financial management

- managing public complaints. ${ }^{16}$

OMDT program-approved institutions offer courses to improve participants' understanding of strategic thinking, transnational policing management, global city management, advanced national

16 Information provided by the HKPF on 11 October 2011. 
studies and strategies, sustainable leadership training, Chinese foreign affairs and national plans. The OVT program offers specialised courses that cannot otherwise be organised in Hong Kong. Examples include Protecting Infrastructure against Terrorism, International Disaster Management, Concealed Human Narcotic Detection, Comprehensive Security Response to Terrorism, Marine Electronics Installer, NMEA 2000 Training and Advanced Management, Dignitary Protective Seminar, Using the Internet as an Intelligence Tool, Terrorism Investigation and Behaviour-Based Safety and Safety Management. The content of the training curriculum reflects the different skills and intellectual capacities the HKPF requires to develop a comprehensive workforce plan. ${ }^{17}$

Two measures taken by the HKPF characterise the distinct nature of training strategies adopted by the Hong Kong civil service sector: the Living-the-Values Workshops and training days. In March 2011, the Force Quality Management Strategy was launched with the aim of achieving continuous improvement.

\section{Living-the-Values Workshops}

In 1997, the Living-the-Values Workshops were rolled out to provide a discussion forum for staff, aimed at:

- promoting awareness and acceptance of HKPF values

- expressing views on areas of concern

- providing feedback to senior management

- providing two-way 'buy-in', both from the top down and from the bottom up.

There have been seven 'waves' of workshops. Wave VII (commencing September 2010) focuses on overcoming barriers to professionalism in a changing world by:

- enhancing officers' awareness of and sensitivity to the need to meet the public's increasing expectations in a rapidly changing society

- enhancing officers' understanding of effective communication with all stakeholders by listening to their needs and explaining their reasoning 
- strengthening officers' belief and efforts in striving for quality service and continuous improvement in their everyday work.

The workshops are organised biannually. This is a HKPF-wide activity involving every member of uniformed staff. Training methods include role-playing, case studies, discussions and presentations. Facilitators are drawn from within the force: an assistant commissioner-level member will be invited to run training sessions for superintendents, a superintendent-level member for inspectors and inspector-level staff for junior police officers. ${ }^{18}$

\section{Training days}

Smaller in scale than the Living-the-Values Workshops are the training days that are scheduled annually and targeted at inspectors and junior police officers. The objectives of training days are to:

- enhance the effectiveness of participating personnel by providing them with job-related training

- facilitate personnel management and good communication

- generate and maintain a culture of living police values, a healthy lifestyle and team spirit

- teach awareness of the local situation as it affects individual job descriptions

- obtain feedback on professional issues of HKPF-wide concern.

Training days normally last a full working day and are held every six to eight weeks at the discretion of formation commanders. A minimum of five training days should be held each year in each formation. There should be no more than 50 officers participating. Training day packages are developed according to the laws, police orders and procedures in place at the time of scheduling. A training and staff relations officer (chief inspectorate rank) leads the activities. Topics covered in 2011 included Integrity Management, Handling Civil Disputes and Emotional Regulation and Working with the Media. 
The 2008 review of the workshops indicated that they should continue as one of the key instruments by which to align personal values with HKPF values, but the workshops should be continuously refined to encourage more bottom-up discussion and self-reflection. ${ }^{19}$ Interviews with a handful of middle-level and junior police officers show they are all highly supportive of the Living-the-Values Workshops and the training days. ${ }^{20}$ These two measures are highly regarded as tools to improve all stakeholder relationships, to reinforce a learning culture within the HKPF, to empower middle-ranking and junior police officers and, most importantly, to create a strong sense of pride, identity, loyalty and commitment to the HKPF.

\section{In summary: Present problems and future challenges}

The determination and dedication of successive HKPF commissioners since the 1970s have transformed the force into Asia's - and probably the world's - finest police force in terms of fighting crime, maintaining law and order and serving the community. The government has spared no effort in supporting the training and development of the police. Among all uniformed services, and indeed all departments, the HKPF has always been provided with generous resources to carry out its work, including the operation of the police college. With the exception of the very top positions in the force, the commissioner and his senior management make decisions on promotion and succession to senior ranks. The senior management identifies high performers at superintendent level and plans possible successions to commissioner level 10-15 years in advance. Every year, the Secretary for the Civil Service reviews the succession plan with the Commissioner of Police. Although the post of Commissioner of Police is a civil service one, it is classed as a principal office (similar to the posts of secretaries) under the Basic Law, so the officer is subject to official appointment by the Central Government of China following nomination by the Chief Executive of the HKSARG.

19 ibid.

20 Interviews conducted in October 2011. 
One legacy of the colonial era is the relatively early retirement age for senior directorate officers of the uniformed services: 57, compared with the normal retirement age of 60 for other civil servants. The normal retirement age of police officers has remained at 55 . With the expansion of university places in recent years, most new recruits now join the HKPF in their early 20s after obtaining their bachelor degree. If they enter at the rank of constable, they have to pass 10 rank promotions to reach the position of chief superintendent; if they join as an inspector, the number of promotions can be reduced to six. The most talented chief superintendent will then have to pass four promotions to reach the top post of commissioner. It is no surprise, then, that the average term of commissioners in the past two decades has been five years or less.

Nowadays, people not only live longer, they also stay healthy for longer. There is a strong case to extend the normal retirement age of Hong Kong civil servants from 60 to perhaps 63 or 65 , and there is certainly an urgent case to extend the retirement age of the uniformed services, including the police, from 55 or 57 to at least 60 .

In addition, while the numerous promotion ranks in the HKPF may be conducive to maintaining morale (so that one is promoted more often), it may not contribute to enhancing efficiency or a more sustainable executive development program. A review of the ranking structure in the HKPF would help to improve efficiency and eliminate unnecessary levels. We should bear in mind that the present strength of the force is about 400 police officers per 100,000 people, which is the highest per capita rate among developed cities (Singapore's police per capita ratio is about half of Hong Kong's).

As a paramilitary force in colonial times, the HKPF carried out its orders without any regard for Chinese nationalistic considerations, as it did during the 1967 riots. After Hong Kong became a Special Administrative Region of China, the Basic Law, created under the Chinese Constitution, conferred a high degree of autonomy to the HKSARG. Hong Kong civil servants do not need to declare their allegiance to the Central Chinese Government; under Article 99 of the Basic Law, they are responsible to the HKSARG only. When the HKSARG introduced the accountability system (which is a politically appointed ministerial system) for the most senior government officials one of its declared objectives was to better preserve the political neutrality of the civil service, including the police. 
Until a few years ago, the impartiality of the police in handling political demonstrations was not questioned. For example, in 2003, when half a million people marched in the streets to protest against the government's proposal to enact legislation to prohibit treason and subversion against China, the police handled the demonstrations fairly and efficiently and not a single accident occurred. More recently, with the present government of Chief Executive, Donald Tsang, implementing some unpopular policies and anti-government demonstrations becoming more confrontational, the police have been accused of impeding some protest actions, particularly when the targets are the Chinese Government or their representative offices in Hong Kong.

The alleged politicisation of the police came to a head when the HKPF was accused of overdoing security arrangements for the visit of then Chinese Vice-Premier Li Keqiang to Hong Kong in August 2011. As a result, the Hong Kong press staged a protest against the severe restrictions put on their reporting and photography work. Several students were allegedly detained by the police in a building within the campus of the University of Hong Kong so they could not join the protest. A person wearing a 'June 4' slogan t-shirt was taken away to the police station as he stepped out from his residence. ${ }^{21}$ These heavyhanded police actions resulted in strong public criticism. The police commissioner was summoned to a meeting of the Legislative Council, the University of Hong Kong conducted an inquiry and the detained students took civil action against the police. The commissioner insisted that he was not under any political pressure nor did he have any political considerations in making the security arrangements.

In the aftermath of this incident, police popularity suffered its worst rating since 1997. According to the University of Hong Kong Public Opinion Program (HKUPOP) survey conducted in September 2011, the proportion of respondents who were satisfied with the performance of the police dropped to a record low of 56.7 per cent, while the figure for those who were unsatisfied rose to a record high of 19.7 per cent. These figures may still be very respectable when compared with those in other jurisdictions but they certainly represent a warning signal to

21 This was in reference to the Tiananmen Square incident on 4 June 1989, when the Chinese Government sent in the military to forcibly quell student demonstrators in Tiananmen Square in Beijing. 
the HKPF. How to stay politically neutral, and be seen as such, will be among the greatest challenges to the incumbent Commissioner of Police and the HKSARG.

In 2010-11, total expenditure on training in the Hong Kong civil service was about HK\$950 million (A $\$ 162$ million) - equivalent to 1.7 per cent of the total payroll. Of this training expenditure, departments spent 80 per cent, with the HKPF accounting for close to half of departmental spending. Although the HKPF is the largest department, with about 28,000 police officers, it still represents less than 20 per cent of the total civil service establishment and yet it accounts for 40 per cent of total government spending on training. The case of police training may offer a good model for other departments to follow provided the HKSARG is prepared to make greater efforts in training its civil servants and doubles its present expenditure on training.

\section{References}

Hong Kong Police College 2006. Training Development Plan 2006-08. Hong Kong: Hong Kong Police College.

Hong Kong Police College 2008a. Common Course Review 2008. EKW V1.3, March. Hong Kong: Hong Kong Police College.

Hong Kong Police College 2008b. Police Training Series 7: Professionalization of police training and development. May. Hong Kong: Hong Kong Police College.

Hong Kong Police College 2009. Training and Development Plan 20092011. Hong Kong: Hong Kong Police College.

Hong Kong Police College 201 la. A Conceptual Framework for Command Courses. Hong Kong: Hong Kong Police College.

Hong Kong Police College 2011b. Challenge in Police Leadership Development. July. Hong Kong: Hong Kong Police College.

Hong Kong Police Force (HKPF) 2010. Hong Kong Police Review 2010. Hong Kong: HKPF. 
This text is taken from Sharpening the Sword of State: Building executive capacities in the public services of the Asia-Pacific, edited by Andrew Podger and John Wanna, published 2016 by ANU Press, The Australian National University, Canberra, Australia. 